\title{
Male Breast Cancer Patients' Perspectives on Their Health Care Situation: A Mixed-Methods Study
}

\author{
Sarah Maria Halbach ${ }^{\mathrm{a}, \mathrm{b}} \quad$ Evamarie Midding ${ }^{\mathrm{a}, \mathrm{b}} \quad$ Nicole Ernstmann $^{\mathrm{a}, \mathrm{b}}$ \\ Rachel Würstlein $^{c}$ Rainer Weber ${ }^{d}$ Sherin Christmann ${ }^{a, b} \quad$ Christoph Kowalski $^{e}$ \\ ${ }^{a}$ Center for Health Communication and Health Service Research (CHSR), Department of Psychosomatic Medicine \\ and Psychotherapy, University Hospital Bonn, Bonn, Germany; ${ }^{b}$ Center for Integrated Oncology, Bonn, Germany; \\ 'Department of Gynecology and Obstetrics, Breast Center and CCCLMU, University of Munich (LMU), Munich,

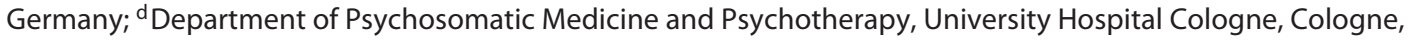 \\ Germany; ${ }^{e}$ German Cancer Society (DKG), Berlin, Germany
}

\section{Keywords}

Male breast cancer $\cdot$ Health services research $\cdot$ Patient care $\cdot$ Mixed methods

\begin{abstract}
Background: Male breast cancer is rare. No information was available on how male breast cancer patients (MBCPs) experience the health care they receive in Germany in a setting that is tailored to women. The aim of this study was to explore the health care situation of MBCPs from their perspectives. Methods: The study follows a mixed-methods design, combining quantitative data from a standardized written questionnaire with qualitative data from personal interviews. Descriptive statistics (quantitative data) and qualitative content analysis (qualitative data) were used for data analysis. Results: Questionnaires completed by 100 and personal interviews of 27 MBCPs were analyzed. Several men reported mainly positive experiences while others experienced shortcomings. These included delays in diagnosis, health care provider uncertainty about treatment (tamoxifen, radiation therapy), experiences of stigmatization, and issues of continuity of care including unclear responsibilities for aftercare and access challenges to breast-cancer-specific care in gynecology settings. Conclusions: The awareness of male breast cancer needs to be increased among the public,
\end{abstract}

health care providers and researchers in order to avoid delays in diagnosis and reduce stigmatization and uncertainty about treatment. Health care structures ensuring access to gynecology care and clear responsibilities for aftercare need to be established.

(c) 2019 S. Karger AG, Basel

\section{Introduction}

Breast cancer in men is rare. It has been estimated that about $1 \%$ of all breast cancer diagnoses are established in men $[1,2]$. For the US, 2,550 new cases of male breast cancer (MBC) and 480 deaths due to the disease were estimated for 2018 [3]. In Germany, 650 new cases of MBC and 134 MBC-related deaths occurred in 2014 [4]. The average age of diagnosis is higher in men than in women (71 vs. 64 in Germany) [4]. Studies indicate that age-adjusted incidence rates have increased over the recent years $[1,5,6]$, while overall mortality has significantly decreased [7, 8]. Giordano [1] has recently summarized the current knowledge on epidemiological, pathological, clinical and treatment-related data for MBC.

Female breast cancer (FBC) receives much public attention, and breast cancer centers offer well-established 
structures for routine care that are specifically tailored to female medical and psychosocial needs. In contrast, there is little public awareness of MBC [9], and specifics regarding the treatment and needs of male breast cancer patients (MBCPs) are rarely known. Although a section on the treatment of $\mathrm{MBC}$ has recently been included in breast cancer clinical guidelines in Germany [10], due to the lack of clinical studies, treatment is still mainly based on the knowledge obtained from treating FBC [1, 7, 11-13].

Several studies conclude that there are differences in health care provision for female breast cancer patients (FBCPs) versus MBCPs. These include, for example, a later stage at diagnosis and a worse overall survival of MBCPs compared to FBCPs as well as different behavior of health care providers (HCPs) when dealing with MBCPs compared to FBCPs $[14,15]$. Due to the rareness of the disease, HCPs may have never been confronted with an MBCP [12]. Lack of HCP knowledge and experiences may affect MBCPs' experiences and uncertainties throughout their cancer journeys. Yet, only a few studies have investigated the psychosocial burden and experiences of MBCPs. MBCPs report experiences of stigmatization [16] and problems regarding their sexual identity and body image $[15,17]$. Many MBCPs perceive the health care situation as specialized to women, especially in terms of information provision [18-20]. Moreover, MBCPs were found to not participate in supportive measures [19,21]. A qualitative study found that MBCPs have a need for increased public and provider awareness, more gender-specific information and the inclusion of MBCPs in research [21]. Kowalski et al. [22] found a higher health-related quality of life in MBCPs than in FBCPs but lower scores in the subscales covering aspects of "role functioning", indicating the need for early psychosocial interventions. Several studies recommend adapting health care provision to the needs of MBCPs $[9,20,21$, 23-25].

Nevertheless, to the best of our current knowledge, there is no study specifically investigating the entire process of $\mathrm{MBC}$ care in Germany. Based on this background, the N-MALE study (male breast cancer: patients' needs in prevention, diagnosis, treatment, rehabilitation and follow-up care) was initiated. First results of the N-MALE study found health care disparities between different states in Germany in terms of access difficulties to gynecology treatment and MBCPs experiencing stigmatization $[16,26]$. In this study, the main results of the $\mathrm{N}$ MALE study are presented. It was aimed to determine the following: How do MBCPs experience the health care situation with respect to every step in the cancer care process from diagnosis to treatment (surgery, chemotherapy, radiation therapy, [anti-]hormone therapy), rehabilitation, and aftercare?

\section{Materials and Methods}

Study Design

The N-MALE study was conducted between 2016 and 2018 and funded by the German Cancer Aid. A cross-sectional mixed-methods observational design was applied combining quantitative data from a standardized postal survey and qualitative data gathered in personal interviews. A mixed-methods approach was chosen since the combination of quantitative and qualitative methods can be used for a comprehensive analysis of the research question: quantitative data allow a comprehensive assessment of factual experiences of a larger sample size. The qualitative approach allows an exploratory assessment of the experiences of MBCPs in Germany and was applied in view of the lack of knowledge in this area. Qualitative data assessment further allows to get a deep insight into MBCPs' experiences. Moreover, using both types of data enables a reciprocal validation of results. The Ethics Committee of the Medical Faculty of the University of Bonn has given approval for the study. Midding et al. [16] reported detailed information on the methods used in the N-MALE study (open access publication).

\section{Sample}

MBCPs were recruited throughout the country via German breast cancer center hospitals, via the self-help network for MBCPs "Männer mit Brustkrebs e.V." and public notices in the media between 2016 and 2017. Inclusion criteria for survey participation were the availability of a written declaration of consent and a confirmed diagnosis of breast cancer (C50.x or D05.x). Additional exclusion criteria for personal interviews were determined as aspects that impede setting up an interview and included speech or comprehension problems, deafness, advanced cancer, psychosis, dementia, and related issues like pain, and difficulties in concentrating. Data from the postal questionnaire were used for the sampling of MBCPs for personal interviews. The sampling for personal interviews was established following the theoretical sampling approach by Glaser and Strauss [27]. This approach aims to identify and include signifying and contrasting cases (e.g., in terms of sociodemographic and disease-related characteristics). Detailed information about sampling criteria used in this study is described elsewhere [16]. Interviews were conducted in a reciprocal process of data collection and data analysis until theoretical saturation was achieved.

\section{Quantitative Data: Measures and Analyses}

The written questionnaire included validated instruments assessing psychosocial and medical aspects of care and self-generated factual items (open and closed questions). They included questions about HCPs being involved in the diagnostic process and aftercare (multiple-choice answer categories and open answer possibility), types of treatment received and the location of treatment (e.g., hospital that is connected to a breast cancer center or not), management between interfaces (e.g., recommendation for rehabilitation measures), and questions about the dates of the first consultation of a physician due to symptoms related to breast cancer and a first suspicion of breast cancer by a physician. A time span was calculated (the date of the first suspicion of breast cancer by a physician up to the date of the first consultation of a physician due to symptoms related to breast cancer). Sociodemographic data were collected with factual single items. The questionnaire was pilot-tested in four pretests with MBCPs. SPSS version 24 (IBM SPSS Statistics, 2016) was used for descriptive statistical analysis.

\section{Qualitative Data: Measures and Analyses}

A semi-structured interview guideline was developed by the interdisciplinary research team, based on Helfferich [28]. The interdisciplinary research team developed and pilot-tested the guideline 
Table 1. Sociodemographic and disease-related sample characteristics

\begin{tabular}{|c|c|c|c|c|c|}
\hline & $n(n)$ & $\%(\%)$ & $\begin{array}{l}\text { Mean } \\
\text { (mean) }\end{array}$ & $\begin{array}{l}\text { Min } \\
(\min )\end{array}$ & $\begin{array}{l}\operatorname{Max} \\
(\max )\end{array}$ \\
\hline \multicolumn{6}{|l|}{ Sociodemographic characteristics } \\
\hline Age in years (missing $2[1]$ ) & & & $66.91(64.8)$ & $39(42)$ & $89(89)$ \\
\hline \multicolumn{6}{|l|}{ Living with a partner (missing: 6 [3]) } \\
\hline Yes & $82(19)$ & $87.2(79.2)$ & & & \\
\hline No & $12(5)$ & $12.8(20.8)$ & & & \\
\hline \multicolumn{6}{|l|}{ Children (missing 6 [1]) } \\
\hline Yes & $79(20)$ & $84.0(76.9)$ & & & \\
\hline No & $15(6)$ & $16.0(23.1)$ & & & \\
\hline \multicolumn{6}{|l|}{ Education (multiple answers possible) (missing $2[1])$} \\
\hline No school-leaving certificate & $2(0)$ & $2.0(0.0)$ & & & \\
\hline Lower school-leaving certificate & $41(11)$ & $41.8(42.3)$ & & & \\
\hline Intermediate school-leaving certificate & $27(8)$ & $27.6(30.8)$ & & & \\
\hline \multicolumn{6}{|l|}{ General or subject-specific university entrance } \\
\hline qualification & $35(11)$ & $35.7(42.3)$ & & & \\
\hline \multicolumn{6}{|c|}{ Disease-related characteristics } \\
\hline \multicolumn{6}{|c|}{ Types of treatment received (multiple answers possible) (missing $0[0]$ ) } \\
\hline Surgery & $97(27)$ & $97.0(100)$ & & & \\
\hline Chemotherapy & $56(16)$ & $56.0(59.3)$ & & & \\
\hline Radiation therapy & $65(16)$ & $65.0(59.3)$ & & & \\
\hline (Anti-)Hormone therapy & $75(22)$ & $75.0(81.5)$ & & & \\
\hline I don't know & $2(1)$ & $2.0(3.7)$ & & & \\
\hline \multicolumn{6}{|l|}{ First diagnosis (missing 4 [2]) } \\
\hline Yes & $92(24)$ & $95.8(96.0)$ & & & \\
\hline No & $4(1)$ & $4.2(4.0)$ & & & \\
\hline Time since first diagnosis (in years) (missing 5 [1]) & & & $3.61(4.1)$ & $<1(<1)$ & $20(17)$ \\
\hline
\end{tabular}

Quantitative sample $n=100$; data of the qualitative sample $(n=27)$ in brackets.

with 3 MBCPs. It included both open questions on every health care setting along the cancer care continuum and a thematic guidance note with pre-set thematic areas and an opportunity for follow-up questions. Interviews were conducted face-to-face and lasted between 1 and $2 \mathrm{~h}$. Interviews were audiotaped and transcribed in accordance with standardized transcription practices [29]. Two scientists of the research team at the University Hospital of Bonn analyzed the transcripts of the interviews following the method of summary qualitative content analysis [30]. Coding was inductive and deductive in order to summarize themes that are of importance for MBCPs in the process of cancer care. Results were discussed in a research workshop at the University Hospital of Bonn. MAXQDA Standard 12 (VERBI Software, 2016) software was used for data analysis.

\section{Results}

\section{Sample Characteristics}

124 MBCPs wished to participate in the study. 3 of these MBCPs were excluded because they did not meet inclusion criteria. Reasons for dropout included death or a wish to withdraw participation because of bad health. 4 MBCPs participated in pretests of the written questionnaire and were therefore excluded from further data collection. 117 MBCPs were thereby eligible for participation and received a postal questionnaire. $103 \mathrm{MBCPs}$ re-

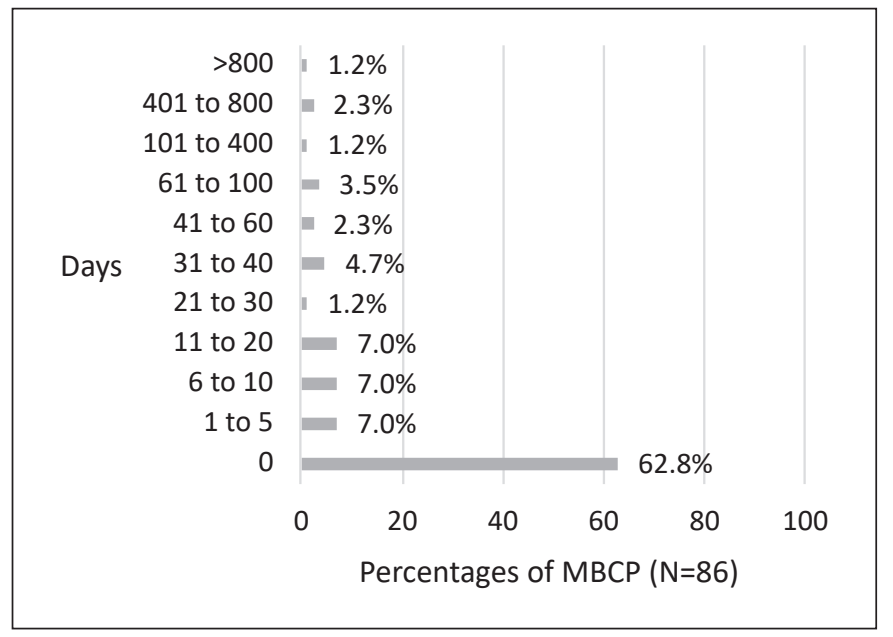

Fig. 1. Time span (in days) between the first consultation of a physician due to symptoms related to breast cancer and the first suspicion of breast cancer by a physician.

turned the questionnaire to the research team (response rate $88.0 \%$ ). Reasons for nonresponse included death of the participant, change of health situation or withdrawal from participation. In addition, 3 questionnaires had an amount of missing values of $\geq 30 \%$ and were excluded 
Table 2. Health care providers involved in the process of diagnosis

\begin{tabular}{|c|c|c|c|c|c|}
\hline \multirow[t]{2}{*}{ Medical disciplines $(n=100)$} & \multicolumn{2}{|c|}{ Yes } & \multicolumn{2}{|l|}{ No } & \multirow{2}{*}{$\begin{array}{l}\text { Missing } \\
n\end{array}$} \\
\hline & $n$ & $\%$ & $n$ & $\%$ & \\
\hline Primary care & 70 & 70.7 & 29 & 29.3 & 1 \\
\hline Outpatient gynecology & 20 & 20.2 & 79 & 79.8 & 1 \\
\hline Mammography center & 43 & 43.0 & 57 & 57.0 & 0 \\
\hline Breast cancer center & 75 & 75.8 & 24 & 24.2 & 1 \\
\hline $\begin{array}{l}\text { Other (open answers: dermatology, urology, surgery, } \\
\text { hospital, radiation center, wife, personal initiative) }\end{array}$ & 19 & 19.2 & 80 & 80.2 & 1 \\
\hline
\end{tabular}

More than one answer possible.

Table 3. Health care professionals involved in aftercare $(n=81)$

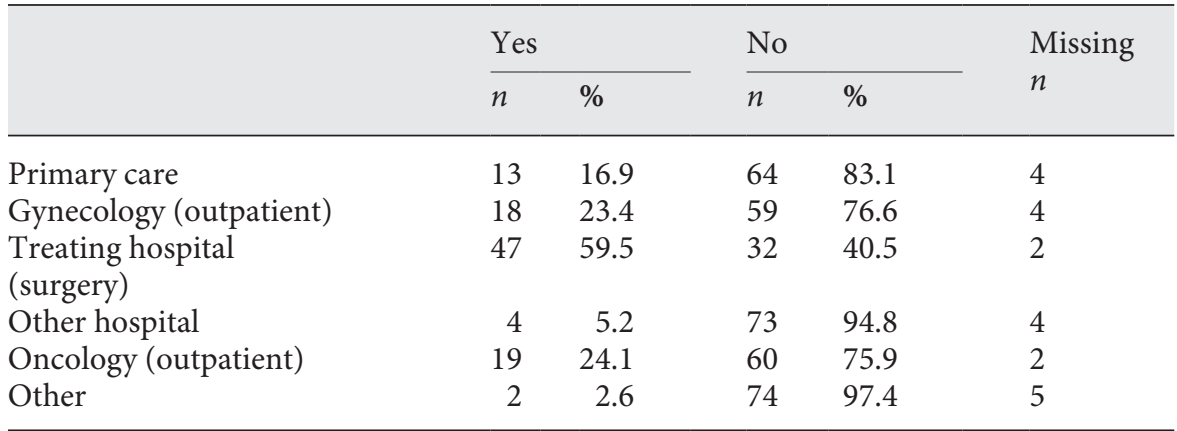

More than one answer possible. from further analysis. Thereby data of $100 \mathrm{MBCPs}$ were included for data analysis (cleared response rate $85.5 \%$ ). Personal interviews were conducted with 27 of these patients. Table 1 gives an overview of the sample characteristics of both the quantitative and the qualitative sample.

\section{Experiences of MBCPs over the Course of the Disease}

Below, quantitative and qualitative results are reported in separate sections along all steps of cancer care (diagnosis, treatment, rehabilitation, and aftercare).

\section{Results of Quantitative Data Analysis}

Table 2 summarizes the results, showing how often which HCPs were involved in the diagnostic process. Primary care (70.7\%) and breast cancer centers $(75.8 \%)$ were the most prevalent HCPs in the diagnostic process. Figure 1 shows the results concerning the time span (in days) between the first consultation of a physician due to symptoms related to breast cancer and a first suspicion of breast cancer by a physician. The mean value was 44.9 days and the median was 0 days $(\mathrm{SD}=186.4$; $\min -\max =$ $0-1,388$ days). In most cases (62.8\%), the physicians assumed that symptoms might be related to breast cancer during the first consultation. 89 (94.7\%) men were treated in breast cancer center hospitals and 5 (5.3\%) men were treated in hospitals not connected to a breast cancer center (missing values $n=6$ ). Results show that 39 of the 56 MBCPs who had chemotherapy (73.6\%; missing values $n=3)$ and 36 of the $65 \mathrm{MBCPs}$ who had radiation therapy $(57.1 \%$, missing values $n=2)$ received it at the same hospital where they underwent surgery. 53 men (54.6\%) participated in a rehabilitation measure ( 2 outpatient; 51 inpatient). Rehabilitation was recommended by primary care physicians $(n=9)$, outpatient gynecologists $(n=1)$, treating hospitals $(n=32)$ (e.g., social counselling service, physicians), outpatient oncologists $(n=6)$ and others ( $n=1$ health insurance company, $n=3$ personal initiative). $81 \mathrm{MBCPs}$ indicated that they received aftercare. Table 3 provides an overview of the HCPs involved in aftercare. Aftercare mostly took place in the same hospital where the surgery had been conducted (59.5\%), followed by outpatient gynecology (23.4\%).

\section{Results of the Qualitative Data Analysis}

Concerning the diagnostic phase, MBCPs reported that they went to see their primary care physician because they or their spouses noticed symptoms like lumps, a bleeding nipple or pain in the breast. The physicians' reactions differed. Some primary care physicians responded quickly and thoroughly and soon expressed the necessity 
for further examination or even directly suspected breast cancer. Consequently, they immediately referred the men to gynecology, mammography or radiology centers:

"Well, my primary care physician already suspected that it could be breast cancer, and therefore, first mammography." (ID 12)

Other men reported that their primary care physicians did not express any suspicion that the symptoms might indicate breast cancer. Either they referred the men to physicians who do not provide breast cancer care (e.g., dermatologists) or they recommended a wait-and-see approach. Some of these misjudgments resulted in delays in the diagnosis. In some cases, the diagnosis was established as late as months or years after the first symptoms arose and partly due to the personal initiative of patients and their spouses:

"Since April 2009, I have been annoying my primary care physician with it and he did not RECOGNIZE it as such." (ID 17) (diagnosis in 2013 at a clinic due to personal initiative)

Some gynecologists misjudged the situation as well:

“(...) the physician who did the surgery at (name of the place) breast cancer center, she hasn't done ANYTHING BUT breast cancer in women for 20 years. And of course ALWAYS with imaging performed before the examination. And I ... before that, I was at a SPECIALIST practice for women that offers screening. And BOTH of them got it wrong. Both didn't quite laugh at me but smiled about me when I asked 'Could it also be breast cancer?"' (ID 87)

Furthermore, men reported access difficulties to gynecology care in the diagnostic phase (and aftercare, see below). Outpatient gynecology practices and hospital gynecology departments including breast cancer centers rejected MBCPs due to billing issues related to treating men:

“(...) the secretary from the gynecology department called and said: ' (...) Well, you are a man; we cannot treat that here at the gynecology department at the HOSPITAL.' (...) And I thought, well I will call a local outpatient gynecologist. They also directly told me: 'We do not treat men in general.' (...) So I slowly started to get nervous." (ID 77)

In the treatment phase - during hospital stay - some men were satisfied overall and did not report any situations differing from routine care. Men felt safe with providers and well informed. Some men reported that they felt in a "special position" during the hospital stay, with the perception of this "special position" differing between men. Several men perceived it in a positive way: They experienced a high level of attention by HCPs, in some cases even leading to the perception that they received more comprehensive treatment (e.g., having a conversation with the chief physician, staying in a single room, more physicians being involved in treatment).
“(...) especially since I did not have to worry. 'Hopefully they did everything right.' (...) The surgeon said: 'So many eyes were watching,' and he said: 'Then, you CANNOT possibly do anything wrong." (ID 17)

In contrast, other men did not feel comfortable with their "special position," e.g., because a single room had to be arranged for a man at the gynecology department:

"Then the women were split up in all these other rooms and I suddenly had a four-bed room for myself. They made an insane effort there" (ID 23)

Others experienced stigmatization during the hospital stay which is described elsewhere [16].

Men did not report any positive or negative experiences that were attributable to being an MBCP during chemotherapy. With regard to radiation therapy, differences from routine care were identified in terms of the indication for radiation therapy for MBCPs. Men criticized that physicians were unsure whether radiation therapy was indicated:

“(...) I had gotten some information myself and I had only read that, in women, if the surgery is not breast conserving, radiation therapy is not carried out after chemo. He (the physician from radiology) was of the opinion that you had to hit it with radiation too. (...) And then the chief of the department came and said to me, I looked at your documents again and I do not think that we should do it. Said you should treat men and women the same and you do not do it in women." (ID 12)

Treatment with tamoxifen ([anti-] hormone therapy) was associated with side effects and uncertainty. Side effects included sweating, hot flushes, aching muscles, joint pain, tingling fingers, sleep disorders, memory loss, sexual dysfunctions, etc. Some men stopped taking tamoxifen due to side effects, while others did not experience any. Men reported HCP uncertainty concerning the side effects, effectiveness and administration period of tamoxifen.

"(...) no one could tell me what the side effects were, of tamoxifen.” (ID 18)

One of the main aspects men reported about the rehabilitation phase was their experience of being the only man around women and how the staff dealt with this. Positive experiences included the opportunity to exchange experiences with female and male (breast cancer) patients as well as positive reactions of female patients:

"And for this, I was just glad, just to hear, how are the WOMEN? How do THEY deal with tamoxifen? Do they also take tamoxifen or do they have anything ELSE? Do they ALSO have the side effects, err, like I have? And, err, I have to say quite honestly, I was VERY glad that I was in a group, just to exchange experiences." (ID 18) 
One man reported being the only man in a group of women and felt like women were thinking:

“This person, it's a man, but it's actually just an affected person.” (ID 22)

In contrast to these experiences, other men felt exotic and excluded from group therapies for women by the clinical staff:

"No. (-) At the water aerobics, I was also the only one. Because they said (-) they do not want, that the women with breast cancer, that there is a, a man. Because some women $(-)$ may not want that (-), yes. I say: "OKAY", I say: (-) "So I'm alone in the swimming pool.” (ID 44)

Positive experiences during aftercare included trust in physicians, regular examinations, and comprehensive instructions about self-examination of the breast. Aftercare was perceived as routine investigations by some men:

"And then the aftercare examination is a process like going to the TÜV (routine car inspection). So routine, (-) nothing more." (ID 42)

Aftercare was also connected to negative experiences such as an unclear distribution of responsibilities: some HCPs did not know who was responsible for aftercare, e.g., the breast cancer center did not give any information about where aftercare could take place.

\footnotetext{
"Because somehow nobody really knew, or it was different for everyone.” (ID 15)
}

Other HCPs did not feel responsible.

"I have survived the cancer now, the surgery, survived the chemo and survived the radiation and now I have no doctor who does the aftercare." (ID 18)

Moreover, instructions for aftercare were lacking. Some MBCPs did not receive any instructions about self-examination of the breast or how often they have to see a physician for aftercare. In this context, men reported that their personal initiative was important. MBCPs independently looked for physicians for aftercare; they had to figure out how often aftercare was necessary and asked for instructions for self-examination of the breast:

“(...) I always ask for it (instructions for self-examination) but she said 'No, we don't need it."' (ID 16)

Access challenges as reported above in the "diagnosis" section were also prevalent during aftercare [26].

\section{Discussion/Conclusion}

The aim of this study was to explore the health care situation of MBCPs in Germany from the patients' perspectives. Results from the analyses of the quantitative and qualitative data of our large and diverse sample of MBCPs show that several aspects of care are well integrated into existing structures of general breast cancer care. However, also shortcomings in several phases of cancer care were identified that are quite similar to those known from other rare diseases [31].

Results from quantitative data analysis reveal that in two thirds of cases, physicians suspected a breast cancer at the first consultation. Qualitative data support these results as several men reported a fast reaction of physicians. However, results from qualitative data analysis also reveal delays in the diagnosis which were mainly caused by HCPs' misinterpretation of breast cancer symptoms and access challenges to gynecology care. France et al. [23] also found delays in the diagnosis in MBCPs that likely reflect that some HCPs are unfamiliar with the clinical picture of MBC. Thomas [9] found that HCPs never talked about the topic of MBC with their male patients even if they had a positive family history of breast cancer. Considering these results and the fact that primary care was involved in the diagnostic process in $70 \%$ of our sample, the importance of primary care as a first point of contact in prevention and patient education is clearly underlined. Moreover, partners and spouses seem to play an important role in noticing breast cancer symptoms in our sample, an observation that is congruent with other findings $[19,32]$ and emphasizes the importance to increase public attention for MBC. As results from quantitative data analysis show, most men were treated (surgery, chemotherapy, radiation therapy) in hospitals connected to a breast cancer center. Qualitative data analysis reveals that MBCPs mainly felt save with the providers. Some MBCPs even felt that they received special attention due to the rarity of their disease, partly even making them feel safer and more comprehensively treated than female patients. Other MBCPs in turn experienced uncertainty: HCPs were partly unsure whether radiation therapy after mastectomy was indicated in men. This result may be explained by the debate about this indication [11]. Stigmatization was a further theme of importance during the main treatment phase (hospital stay) [16]. Qualitative data analysis further shows that HCPs and MBCPs were unsure about tamoxifen treatment. Some men felt left alone and not informed about tamoxifen. Adjuvant treatment with tamoxifen is considered the gold standard and is associated with an overall better survival in comparison to treatment with aromatase inhibitors [33,34]. Uncertainty about tamoxifen treatment in men might contribute to nonadherence, which is in turn associated with worse medical outcomes, such as shorter time to recurrence (in FBCPs) 
[35]. Results by Oke et al. [36] support this assumption. They found a high percentage of $61 \%$ of elderly MBCPs not continuously taking tamoxifen up to the recommended 5 years. As shown in quantitative data analysis, about half of the MBCPs participated in an inpatient rehabilitation measure, a slightly lower number compared to FBCPs [37]. Some men reported to feel welcomed by other female patients. Others reported experiences of stigmatization (e.g., exclusion from group therapies). Stigmatization was more often caused by HCP uncertainty than by other patients. Detailed information about stigmatization experiences of our sample of MBCPs is reported elsewhere [16]. Aftercare mostly took place in the same hospital where the surgery had been conducted as shown in quantitative data analysis. However, MBCPs reported in the personal interviews that responsibilities for aftercare were unclear. Some MBCPs even had to insist in order to find a provider who felt responsible for aftercare and figure out on their own how often aftercare examinations were necessary. Moreover, access challenges to gynecology care occurred as also found during the diagnostic phase. These shortcomings can keep MBCPs from receiving a timely diagnosis or continuous specialized treatment, which in turn may seriously affect patient prognosis and survival [19,38]. Quincey et al. [39] also found MBCPs to be dissatisfied with the lack of specific structures for their aftercare and treatment.

All in all and in contrast to patients with other rare diseases, MBCPs are likely to benefit from the extensive knowledge and existing structures for general breast cancer care. However, shortcomings and uncertainties exist, especially during the diagnostic phase and aftercare.

This study has several strengths and limitations. Strengths include the comparatively large sample size of $100 \mathrm{MBCPs}$, the high response rate (quantitative data), the diverse sample (qualitative data) and the combined analysis of these data, applying a mixed-methods design. Limitations of the study include differences between participants in terms of their years since diagnosis. Some participants received their diagnosis several years ago. Hence, there is some risk of recall bias, and the health care situation for $\mathrm{MBC}$ might have changed over recent years. Other MBCPs were only recently diagnosed and received their main treatment during the study period. Since their treatment had not been completed, it is not possible to draw any conclusions about whether all participants received the recommended treatment (e.g., aftercare, rehabilitation measures). Moreover, further research may be necessary to see whether the findings translate to other health care systems since health care in Germany is characterized by a separation of the inpatient and outpatient sector. However, a rare disease such as $\mathrm{MBC}$ is likely to be associated with HCP uncertainty and missing health care structures in several health care systems.
In order to reduce negative experiences and thereby improve the health care situation for MBCPs, we recommend the following approaches:

1. Awareness of MBC among the public as well as within the health care system should be increased in order to avoid delays in diagnosis and reduce stigmatization $[16,17,23,40]$. Especially primary care providers need to be trained regarding the clinical picture of $\mathrm{MBC}$ in order to initiate treatment processes at an early time. Palpation results at the male breast always require further investigation [41].

2. Breast cancer research should include men, especially regarding differences in tamoxifen treatment between men and women and the indication of radiation therapy in men.

3. Information material tailored to MBCPs' needs should be developed and provided.

4. Responsibilities of providers for aftercare need to be clarified and transitions between different steps in the cancer care continuum need to be clearly managed.

5. Unrestricted and comprehensive access to gynecology care for MBCPs has to be ensured [26].

\section{Acknowledgement}

We would like to thank all participants of the N-MALE study for sharing their experiences. We would further like to thank all breast cancer centers, the self-help network "Netzwerk Männer mit Brustkrebs e.V." and all those involved in supporting the study and recruiting participants. Our thanks also go to our colleagues Lydia Chorus, Christian Heuser, and Hannah Nakata for all their support.

\section{Statement of Ethics}

The Ethics Committee of the Medical Faculty of the University of Bonn has given approval for the study.

\section{Disclosure Statement}

Christoph Kowalski is an employee of the German Cancer Society. Sarah Halbach received a fee for her talk at a conference of the professional association of breast care nurses.

\section{Funding Sources}

This work was supported by the German Cancer Aid under grant No. 111742. 


\section{References}

1 Giordano SH. Breast cancer in men. N Engl J Med. 2018 Jun;378(24):2311-20.

2 Miao H, Verkooijen HM, Chia KS, Bouchardy C, Pukkala E, Larønningen S, et al. Incidence and outcome of male breast cancer: an international population-based study. J Clin Oncol. 2011 Nov;29(33):4381-6.

3 Siegel RL, Miller KD, Jemal A. Cancer statistics, 2018. CA Cancer J Clin. 2018 Jan;68(1): 7-30.

4 Robert Koch-Institut und die Gesellschaft der epidemiologischen Krebsregister in Deutschland e.V., editors. Krebs in Deutschland für 2013/2014. 11th ed. Berlin: Robert Koch-Institut; 2017.

5 Giordano SH, Cohen DS, Buzdar AU, Perkins G, Hortobagyi GN. Breast carcinoma in men: a population-based study. Cancer. $2004 \mathrm{Jul}$; 101(1):51-7.

6 White J, Kearins O, Dodwell D, Horgan K, Hanby AM, Speirs V. Male breast carcinoma: increased awareness needed. Breast Cancer Res. 2011 Sep;13(5):219.

7 Cardoso F, Bartlett JM, Slaets L, van Deurzen $\mathrm{CH}$, van Leeuwen-Stok E, Porter $\mathrm{P}$, et al. Characterization of male breast cancer: results of the EORTC 10085/TBCRC/BIG/ NABCG International Male Breast Cancer Program. Ann Oncol. 2018 Feb;29(2):405-17.

8 Korde LA, Zujewski JA, Kamin L, Giordano S, Domchek S, Anderson WF, et al. Multidisciplinary meeting on male breast cancer: summary and research recommendations. J Clin Oncol. 2010 Apr;28(12):2114-22.

9 Thomas E. Original Research: men's awareness and knowledge of male breast cancer. Am J Nurs. 2010 Oct;110(10):32-7.

10 Leitlinienprogramm Onkologie (Deutsche Krebsgesellschaft, Deutsche Krebshilfe, AWMF). S3-Leitlinie Früherkennung, Diagnose, Therapie und Nachsorge des Mammakarzinoms, Version 4.1, 2018 AWMF Registernummer: 032-045OL [cited 2019 Jan 3]. Available from: http://www.leitlinienprogrammonkologie.de/leitlinien/mammakarzinom/.

11 Losurdo A, Rota S, Gullo G, Masci G, Torrisi $\mathrm{R}$, Bottai $\mathrm{G}$, et al. Controversies in clinicopathological characteristics and treatment strategies of male breast cancer: A review of the literature. Crit Rev Oncol Hematol. 2017 May;113:283-91.

12 Fentiman IS. Unmet needs of men with breast cancer. Eur J Surg Oncol. 2018 Aug;44(8): 1123-6.

13 Kiluk JV, Lee MC, Park CK, Meade T, Minton S, Harris E, et al. Male breast cancer: management and follow-up recommendations. Breast J. 2011 Sep-Oct;17(5):503-9.
14 Lautrup MD, Thorup SS, Jensen V, Bokmand S, Haugaard K, Hoejris I, et al. Male breast cancer: a nation-wide population-based comparison with female breast cancer. Acta Oncol. 2018 May;57(5):613-21.

15 Robinson JD, Metoyer KP Jr, Bhayani N. Breast cancer in men: a need for psychological intervention. J Clin Psychol Med Settings. 2008 Jun;15(2):134-9.

16 Midding E, Halbach SM, Kowalski C, Weber R, Würstlein R, Ernstmann N. Men With a "Woman's Disease": Stigmatization of Male Breast Cancer Patients-A Mixed Methods Analysis. Am J Men Health. 2018 Nov;12(6): 2194-207.

17 Kipling M, Ralph JE, Callanan K. Psychological impact of male breast disorders: literature review and survey results. Breast Care (Basel). 2014 Feb;9(1):29-33.

18 Brain K, Williams B, Iredale R, France L, Gray J. Psychological distress in men with breast cancer. J Clin Oncol. 2006 Jan;24(1):95-101.

19 Iredale R, Brain K, Williams B, France E, Gray $J$. The experiences of men with breast cancer in the United Kingdom. Eur J Cancer. 2006 Feb;42(3):334-41.

20 Williams BG, Iredale R, Brain K, France E, Barrett-Lee P, Gray J. Experiences of men with breast cancer: an exploratory focus group study. Br J Cancer. 2003 Nov;89(10): 1834-6.

21 Pituskin E, Williams B, Au HJ, Martin-McDonald K. Experiences of men with breast cancer: A qualitative study. J Mens Health Gend. 2007;4(1):44-51.

22 Kowalski C, Steffen P, Ernstmann N, Wuerstlein R, Harbeck N, Pfaff H. Health-related quality of life in male breast cancer patients. Breast Cancer Res Treat. 2012 Jun;133(2): 753-7.

23 France L, Michie S, Barrett-Lee P, Brain K, Harper P, Gray J. Male cancer: a qualitative study of male breast cancer. Breast. 2000 Dec; 9(6):343-8.

24 Fentiman IS, Fourquet A, Hortobagyi GN. Male breast cancer. Lancet. 2006 Feb; 367(9510):595-604.

25 Rudlowski C. Male breast cancer. Breast Care (Basel). 2008;3(3):183-9.

26 Halbach S, Midding E, Wesselmann S, Würstlein R, Ernstmann N. Inanspruchnahme gynäkologischer Facharztleistungen durch Männer mit Brustkrebs(-verdacht). Forum. 2018;33(3):156.

27 Glaser BG, Strauss AL. Grounded Theory: Strategien qualitativer Forschung. Bern: Huber; 2008.
28 Helfferich C. Die Qualität qualitativer Daten: Manual für die Durchführung qualitativer Interviews. 4th ed. Wiesbaden: VS Verlag für Sozialwissenschaften / Springer Fachmedien Wiesbaden GmbH Wiesbaden; 2011.

29 Fuss S, Karbach U. Grundlagen der Transkription: Eine praktische Einführung. Opladen: Budrich; 2014. German.

30 Mayring P. Einführung in die qualitative Sozialforschung: Eine Anleitung zu qualitativem Denken. 6th ed. Weinheim: Beltz; 2016.

31 Garau R. The medical experience of a patient with a rare disease and her family. Orphanet J Rare Dis. 2016 Feb;11(1):19.

32 Adekolujo OS, Tadisina S, Koduru U, Gernand J, Smith SJ, Kakarala RR. Impact of Marital Status on Tumor Stage at Diagnosis and on Survival in Male Breast Cancer. Am J Men Health. 2017 Jul;11(4):1190-9.

33 Fentiman IS. Male breast cancer is not congruent with the female disease. Crit Rev Oncol Hematol. 2016 May;101:119-24.

34 Massarweh SA, Choi GL. Special considerations in the evaluation and management of breast cancer in men. Curr Probl Cancer. 2016 Mar - Aug;40(2-4):163-71.

35 McCowan C, Wang S, Thompson AM, Makubate B, Petrie DJ. The value of high adherence to tamoxifen in women with breast cancer: a community-based cohort study. Br J Cancer. 2013 Sep;109(5):1172-80.

36 Oke O, Niu J, Chavez-MacGregor M, Zhao H, Giordano SH. Adjuvant tamoxifen adherence in men with early stage breast cancer. J Clin Oncol. 2018;36(15_suppl):550.

37 Geyer S, Schlanstedt-Jahn U. Gibt es soziale Ungleichheiten in der Inanspruchnahme der onkologischen Rehabilitation bei Mammakarzinompatientinnen? Gesundheitswesen. 2012 Feb;74(2):71-8.

38 Klein J, Ji M, Rea NK, Stoodt G. Differences in male breast cancer stage, tumor size at diagnosis, and survival rate between metropolitan and nonmetropolitan regions. Am J Men Health. 2011 Sep;5(5):430-7.

39 Quincey K, Williamson I, Winstanley S. "Marginalised malignancies:" A qualitative synthesis of men's accounts of living with breast cancer. Soc Sci Med. 2016 Jan; 149:1725.

40 Johansen Taber KA, Morisy LR, Osbahr AJ 3rd, Dickinson BD. Male breast cancer: risk factors, diagnosis, and management (Review) [Review]. Oncol Rep. 2010 Nov;24(5):111520.

41 Würstlein R, Hesse A, König A, Schulte-Vorwick F, Schredi S, Dietsch N, et al. Tastbefund an der Brust: auch bei Männern immer abklären. Gynäkol Gebursthilfe. 2018;2(23):257. 